\title{
CHARACTERISTICS OF CARBIDE INTERFACIAL LAYER FORMED DURING DEPOSITION OF DLC FILMS ON 316L STAINLESS STEEL SUBSTRATE
}

\begin{abstract}
The paper presents the analysis of formation of interfacial layer during deposition of diamond like carbon film (DLC) on the 316L stainless steel by capacitive plasma discharge in the $\mathrm{CH}_{4}$ atmosphere. The structure of the interfacial layer of DLC film was strongly affected by the temperature increase during the initial stages of the process. Initially, thin interfacial layer of $5 \mathrm{~nm}$ has been formed. As the temperature had reached $210^{\circ} \mathrm{C}$, the second phase of the process was marked by the onset of carbon atoms diffusion into the steel and by the interface thickness increase. Finally, the growth of chromium carbide interface, the upward diffusion of chromium and nickel atoms to film, the etching and the decrease of the DLC film thickness were observed at $233^{\circ} \mathrm{C}$. These investigations were carried out ex-situ by spectroscopic ellipsometry, X-ray diffraction, X-ray photoelectron spectroscopy and Raman spectroscopy.
\end{abstract}

Keywords: RF PECVD, carbon films, diamond like carbon, film growth, carbides formation

\section{Introduction}

Carbon-based thin films such as diamond like carbon (DLC) are being increasingly considered for numerous emerging technologies and applications. DLC is a general term for a group of amorphous, in most cases hydronegenated and metastable, materials containing a mixture of $s p^{3}, s p^{2}$ and sometimes even $s p^{1}$ coordinated carbon atoms [1,2]. Fabrication of such film systems requires control of the deposition process in order to achieve specific microstructure and desirable tribological, electrical, thermal characteristics. These films have also shown good blood compatibility, which is very important in the development of biomedical devices and implant. This field of research has been expanding rapidly over the last decades (see, for example, refs. [3-6]).

In a particular case of DLC films deposited on metallic substrates (implants), different thermal expansion coefficients may generate high compressive stress in a cooling phase. These high stress levels have several consequences, the major set-back is a low adhesion or delamination, particularly when the film is relatively thick $[7,8]$. Formation of a proper interfacial layers between metallic substrate and deposited films can be reduced by the delamination tendency.

Grade 316L stainless steel characterized by high corrosion resistance and therefore being widely used as a base material for medical implants. However, this austenitic steel has relatively poor mechanical properties that can be enhanced by surface treatment, such as carburizing and deposition of DLC films. The solu- bility of carbon in the austenite phase is a temperature-dependent process and care must be taken in order to prepare film interface. It was shown [9-11] that by the substrate temperature limiting to $500^{\circ} \mathrm{C}$ it is possible to diffuse the carbon within the austenitic phase of $316 \mathrm{~L}$ stainless steel without formation of chromium carbides, which reduce the corrosion resistance of this material. For successful industrial applications of plasma treatment of the 316L stainless steel, it is important to find the detailed relation between the process parameters and the properties of modified surface layer. In the present work, the formation of interfacial layers during the deposition of DLC films on the $316 \mathrm{~L}$ stainless steel using low pressure capacitive radio frequency (RF) plasma discharge is investigated. In order to evaluate the effect of process parameters, several ex-situ investigations were carried out; by spectroscopic ellipsometry, X-ray diffraction, X-ray photoelectron spectroscopy and Raman spectroscopy.

\section{Experimental}

\subsection{Deposition process}

The carbon films were prepared on 316L stainless steel substrate with the help of radio frequency (RF, $13.56 \mathrm{MHz}$ ) plasma discharge in the vacuum system described in detail elsewhere [12,13]. Substrates were cylindrical specimens with a diameter of $10 \mathrm{~mm}$. Their flat surface was mechanically ground, polished, ultrasonically cleaned and washed in acetone. Before

\footnotetext{
LODZ UNIVERSITY OF TECHNOLOGY, INSTITUTE OF MATERIALS SCIENCE AND ENGINEERING, STEFANOWSKIEGO 1/15, 90-924 LODZ, POLAND 
the process, the substrates were also cleaned by ion sputtering in a high intensity RF plasma discharge during 4 min at $700 \mathrm{~V}$ and $5 \mathrm{~Pa}$ of residual pressure. Deposition has been performed at $13 \mathrm{~Pa}$ pressure using pure $\mathrm{CH}_{4}$ atmosphere. During the process the negative self-bias of $900 \mathrm{~V}$ was developed on the electrode. The substrate temperature was being monitored by a pyrometer. Table 1 shows value of temperature obtained at the end of film deposition process considered in this work.

TABLE 1

Value of surface temperature measured at the end of film deposition process performed in RF PECVD system

\begin{tabular}{|c|c|c|}
\hline \hline No & Deposition time [min] & Substrate temperature $\left[{ }^{\circ} \mathbf{C}\right]$ \\
\hline 1 & 8 & 178 \\
\hline 2 & 11 & 196 \\
\hline 3 & 14 & 210 \\
\hline 4 & 17 & 222 \\
\hline 5 & 20 & 233 \\
\hline
\end{tabular}

\subsection{Surface characterization}

The thickness of the diamond-like carbon film $\left(d_{f}\right)$ and of the interface $\left(d_{i}\right)$ were determined by variable angle spectroscopic ellipsometer (VASE, J.A. Woollam Co). The investigated wavelength in the visible (VIS) and near infrared (NIR) ranged from 300 to $1600 \mathrm{~nm}$ using angles of incidence of $55^{\circ}, 65^{\circ}$ and $75^{\circ}$. The measured values of the refractive index $(n)$ and extinction coefficient $(k)$ were interpreted in terms of ellipsometric model [14] and fitted using the WVASE software (J.A.Woollam Co.Inc.). The optical model consisted of three layers on the top of the metallic substrate. The top-most layer was simulating by the surface roughness using the effective medium approximation (EMA), mixing $50 \%$ volume of carbon film bulk material with $50 \%$ volume of void. The carbon layer was modelled by gradient layer of combination Lorentz-Drude dispersion model [15], which is usually used in analysis of semiconductor materials [16]. Below the carbon layer was the interfacial layer described by EMA that combined the optical properties of steel and the carbon layer $-50 \%$ volume of steel substrate and $50 \%$ volume of film bulk material above.

Surface microstructure was determined by glancing angle X-ray diffraction (XRD, Philips X'pert diffractometer) at room temperature with an angle of incidence of $0.5^{\circ}$. The XRD patterns were recorded using $\mathrm{Cu}-\mathrm{K}_{\alpha}(1.5406 \AA)$ radiation at $50 \mathrm{kV}$ and $40 \mathrm{~mA}$. The diffraction angle varied between $20^{\circ}$ and $100^{\circ}$, and a divergence slit of $1^{\circ}$ was used to obtain an acceptable signal intensity for relatively short acquisition times. Raman scattering spectroscopy was performed with a Jobin-Yvon T64000 system using an $\mathrm{Ar}^{+}-$ion laser $(\lambda=514 \mathrm{~nm})$ in backscattering geometry. The spectrometer was equipped with $200 \mathrm{~mW}$ laser with a spot size of $1 \mu \mathrm{m}$ in diameter. The investigated wavenumber ranged from 799 to $1800 \mathrm{~cm}^{-1}$. All measurements were carried out in air at room temperature. The depth profile of chemical analysis of structure DLC films and steel substrate were performed by X-ray photoelectron spectroscopy (XPS, PHI 5000 VERSA ProbeTM), operating with $\mathrm{Al} \mathrm{K}_{\alpha}$ radiation $(h v=1486.6 \mathrm{eV})$. The sputtering was performed with $\mathrm{Ar}^{+}$ion bombardment, at a beam voltage of $2 \mathrm{kV}$ and sputter area of $2 \times 2 \mathrm{~mm}^{2}$.

The hardness $(H)$ and Young's modulus $(E)$ were determined from the load-displacement curves (from 20 indentations) measured by a depth-sensing indentation system (Triboindenter, Hysitron, Inc.), using the approach of Oliver and Pharr [17]. The friction coefficient $(\mu)$ was measured using the micro scratch tester (MST, CSEM) with a Rockwell C diamond stylus with $200 \mu \mathrm{m}$ radius that was pulled over a distance of $10 \mathrm{~mm}$ at an applied constant load of $1 \mathrm{~N}$ [18]. The tests were performed at room temperature and at about $40 \%$ humidity.

\section{Results and discussion}

Spectroscopic ellipsometry measurements allowed on calculate the thickness of carbon film and the interface from the optical model describing the thin film system formed on $316 \mathrm{~L}$ stainless steel. Thickness of these layers of compound films is shown in Fig. 1 as a function of treatment time (correlation between time of RF PECVD process and temperature substrate obtained at the end of its shows Table 1). In the initial period, film thickness increases with time and the carbon layer achieves thickness of $120 \mathrm{~nm}$ at substrate temperature of $222^{\circ} \mathrm{C}$. Then, for longer process time thickness of carbon film decreases, whereas thickness of interfacial layer and substrate temperature steadily increases. This result is consistent with Keudell and Jacob's experiment [19]. They observed a change from deposition to erosion at substrate temperature of $225^{\circ} \mathrm{C}$. This temperature marks the onset of the increased diffusion of carbon atoms into the substrate. At this temperature, the interfacial layer increased the thickness three times from about 10 to $30 \mathrm{~nm}$.

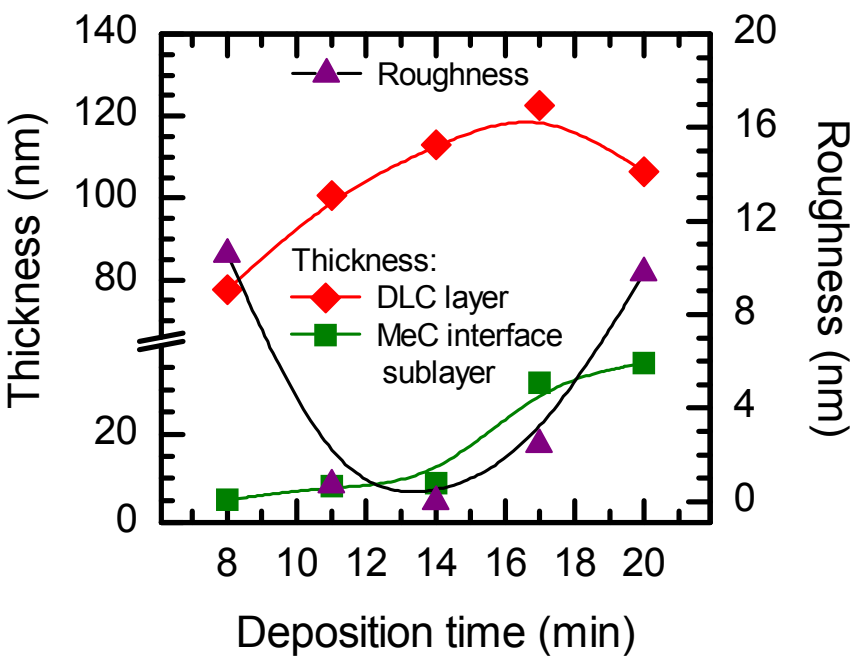

Fig. 1. Thickness of different layers of substrate/film system as a function of deposition time, measured by ellipsometry

The formation of crystalline structure was investigated by XRD. Figure 2 shows the XRD spectra of films for different 
deposition times where various diffraction peaks corresponding to different crystalline structures of modified surface can be observed. At 8 minute of the process the diffraction peaks can be attributed to carbine identified as chaoite at $2 \theta=35.7^{\circ}$, and diamond at $2 \theta=43.8^{\circ}$ and $75.3^{\circ}$ [5]. With the increase of the deposition time, the carbine peak identified as chaoite at $2 \theta=36^{\circ}$ does not increase its intensity, on the contrary to peak at $2 \theta=43.8^{\circ}$. This peak is the conglomeration of a few peaks between 41 and $452 \theta$ angles, the existence of which is clearly showed in enlargement, for treatment process performed during 17 min (Fig. 3). After fitted by four Lorentz line the separated diffraction peaks have been attributed to (510) $\mathrm{Cr}_{3} \mathrm{C}_{2}$, (304) Chaoite, (111) Diamond and (420) $\mathrm{Cr}_{3} \mathrm{C}_{2}$.

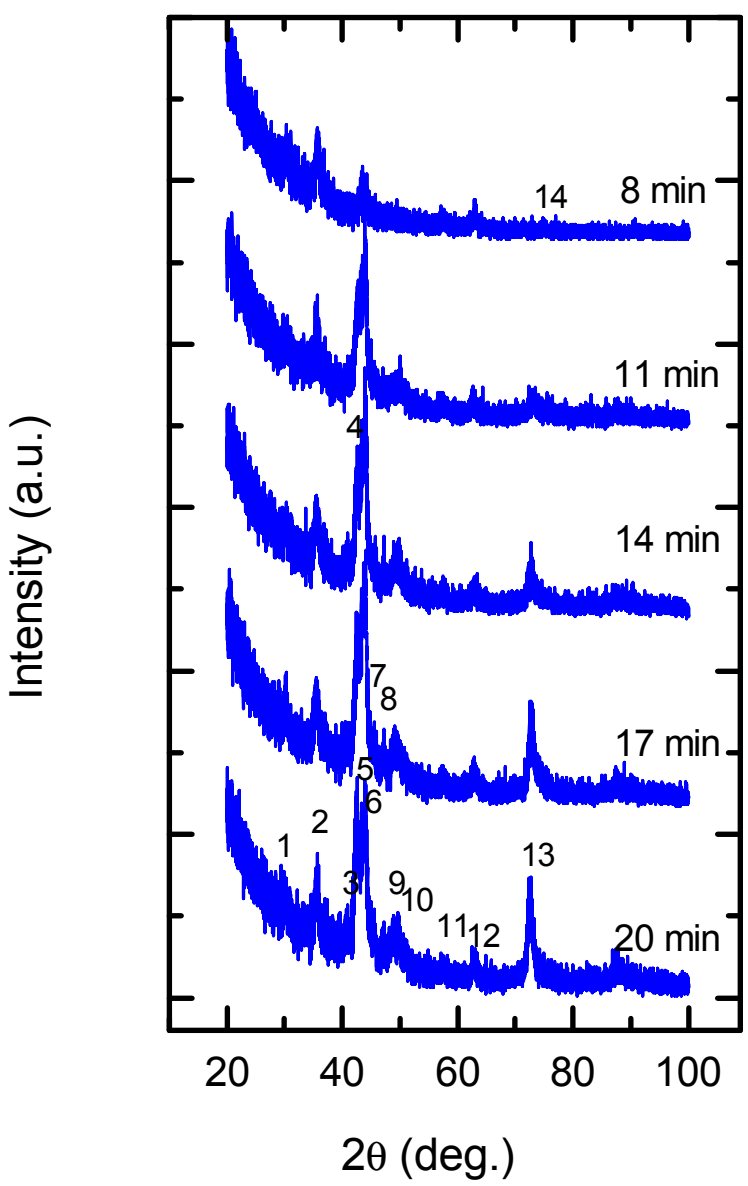

Fig. 2. Effect of deposition time on the crystallographic structure (1 carbine identified as (201) Chaoite, $2-(010) \mathrm{FeC}, 3-(320) \mathrm{Cr}_{3} \mathrm{C}_{2}$, 4 - (510) $\mathrm{Cr}_{3} \mathrm{C}_{2}, 5$ - carbine identified as (304) Chaoite, $6-(111)$ Diamond, 7 - (420) $\mathrm{Cr}_{3} \mathrm{C}_{2}, 8$ - (211) $\mathrm{Fe}_{3} \mathrm{C}, 9$ - (113) $\mathrm{Fe}_{3} \mathrm{C}, 10-(112)$ $\mathrm{Fe}_{3} \mathrm{C}, 11-(123) \mathrm{Fe}_{3} \mathrm{C}, 12$ - (102) Lonsdaleite, $13-(340) \mathrm{Cr}_{3} \mathrm{C}_{2}, 14$ - (220) Diamond)

The nucleation of diamond grain has been observed in gaze faze of radio frequency discharge [20]. Because the distance between crystallographic plane (111) of diamond and (510) $\mathrm{Cr}_{3} \mathrm{C}_{2}$ is almost the same, it is possible to assume that chromium carbide grows on anchored to substrate small particle of diamond. The grain size (calculated by the Debye-Scherrer formula [21]) of (510) $\mathrm{Cr}_{3} \mathrm{C}_{2}$ obtained on the basis of four Lorentz line analyze is always smaller than diamond, and does not depend on the deposition time. That means that diffusion of carbon atom to grain of substrate is limited (maximum carbon solubility in one direction) and flux of carbon atom from plasma and growing film lead to carburization process on boundary grains (where the concentration of chromium atoms is higher that inside of grain) of substrate and changes the interfacial layer thickness.

The thickness of interfacial layer is strongly connected with broad diffraction peak attributed to (340) $\mathrm{Cr}_{3} \mathrm{C}_{2}$ (Fig. 2). The value of the grain size calculated from this peak increases from ca. 2 to $10 \mathrm{~nm}$ and changes in the same way as thickness of the interfacial layers (Fig. 4) with sharp change of one of them ensues at $210^{\circ} \mathrm{C}$ at the final temperature of deposition process. This analysis of (510) and (340) $\mathrm{Cr}_{3} \mathrm{C}_{2}$ diffraction peaks places emphasis on the role of substrate structure and composition on the growth mechanism of carbon film and interfacial layer. Higher concentration of chromium atoms on boundary grains of 316L stainless steel substrate and higher kinship with carbon lead to the creation of chromium carbides in contrast to iron carbides (Fig. 2), identified as $\mathrm{Fe}_{3} \mathrm{C}$ (common hardening constituent in carbon steels) [22]. Peaks characteristic for (113) $\mathrm{Fe}_{3} \mathrm{C}$, and (112) $\mathrm{Fe}_{3} \mathrm{C}$ at around $2 \theta=49^{\circ}$ appear clearly at 14 min., i.e., at the onset of the increased carbon diffusion. But their intensity change was not correlated to the rapid increase of interfacial layer thickness. To recapitulate, to create iron carbides we need higher temperature and in our case peaks attributed to iron carbides appeared on XRD spectra when final substrate temperature had exceeded $210^{\circ} \mathrm{C}$.

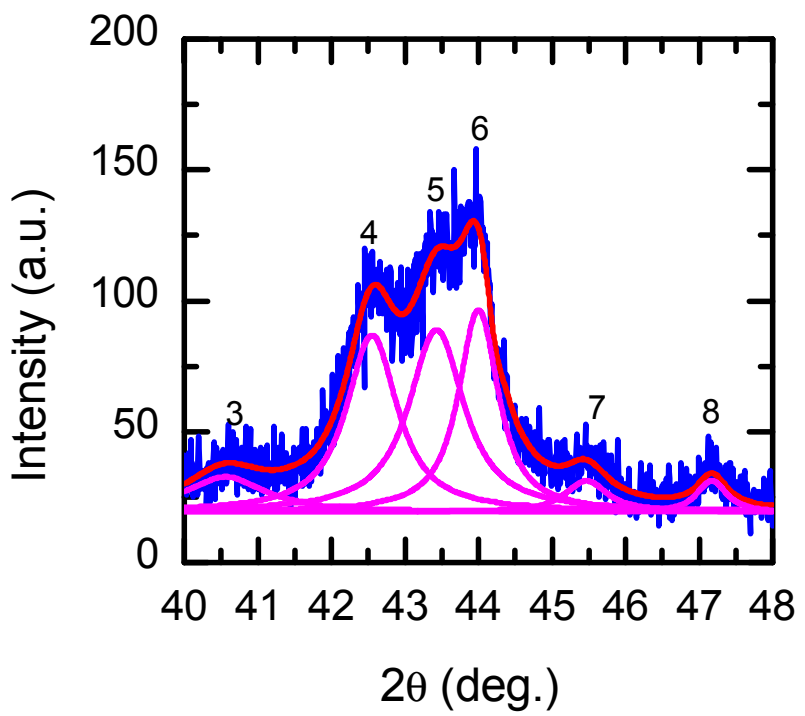

Fig. 3. Enlargement of XRD spectra performed at 17 minutes deposition process (at $222^{\circ} \mathrm{C}$ final surface temperature) showed conglomeration few peaks between 41 and $452 \theta$ angles (Description of XRD peaks is consistent with presented in Fig. 2)

Figure 4 shows the comparison of grain size calculated from (340) $\mathrm{Cr}_{3} \mathrm{C}_{2}$ diffraction peaks with thickness of interfacial layer obtained from analysis of ellipsometry data. It is questionable that high value of interfacial layer thickness $\left(d_{i} \sim 30 \mathrm{~nm}\right)$ formed between DLC film and steel substrate - the ellipsometry measurements are limited by high absorption coefficient of 
electromagnetic wave by steel substrate. In order to eliminate this doubt, the depth profile of structure the DLC films and steel substrate was performed by XPS. Obtained results confirmed the value of thickness of interfacial layer based on metals carbides (Fig. 4), whereas the diffusion of carbon atoms is a few time higher. For example, in the case of films deposited at high final surface temperature (the longest deposition process with $d_{i} \sim 30 \mathrm{~nm}$ ) the deep of diffusion of carbon atoms is estimate at $200 \mathrm{~nm}$ (Fig. 5). Moreover, the detailed analysis of intensity profiles of select steel substrate element shows correlation between diffusion deep of carbon atoms and shape of chromium profile - where intensity of $\mathrm{Cr}$ atoms decrease in substrate. These minimum under "boundary" of steel substrate and DLC film accompany the maximum of concentration $\mathrm{Cr}$ atoms at the bottom of film. This upward diffusion of $\mathrm{Cr}$ can be explained by high mobility of $\mathrm{Cr}$ atoms leading to quick formation chromium carbides observed on XRD spectra (Fig. 2).
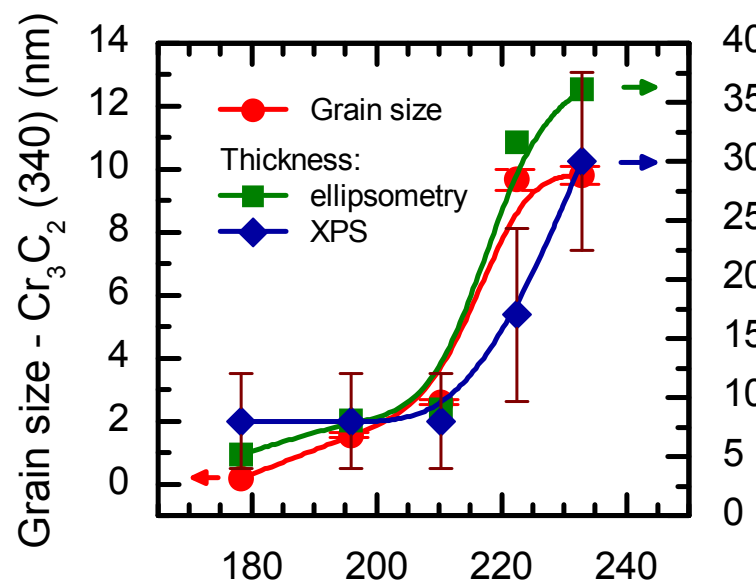

\section{Substrate temperature $\left({ }^{\circ} \mathrm{C}\right)$}

Fig. 4. The grain size calculated at (340) $\mathrm{Cr}_{3} \mathrm{C}_{2}$ plane and thickness carbide sublayer obtained from ellipsometry and XPS measurements as a function of final deposition temperature

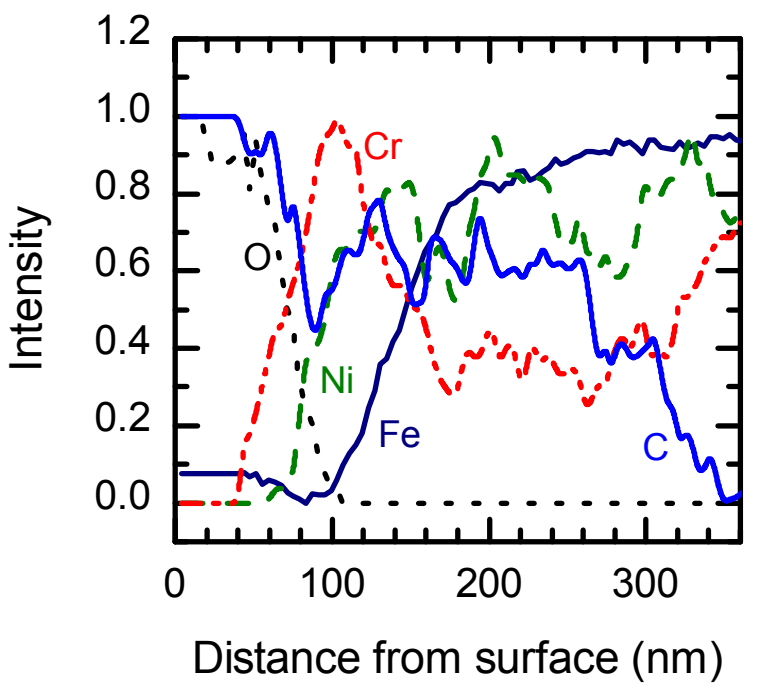

Fig. 5. The curves described profile of normalize intensity the oxygen and select element of steel substrate obtained by XPS measurements for deposition process performed at $233^{\circ} \mathrm{C}$ final surface temperature
The upward diffusion into films was also observed in the case nickel atoms (Fig. 5). However, in comparison to $\mathrm{Cr}$ the penetration by $\mathrm{Ni}$ atoms is lower and does not influence of carbides formation. There presence in film provides contribution to change the optical constants of DLC film.

Based on spectroscopic ellipsometer measurements the optical constants were calculated. In the model was assumed that refractive index $(n)$ and the extinction coefficient $(k)$ of DLC films change in gradually way with thickness [16] as results of etching process, caused by increase surface temperature during deposition of films. Obtained results of fitting shows that value of optical constants of DLC films are strongly dependent on the deposition time [6], and confirm that deposited films are inhomogeneous with one exception. Namely, in the case of film deposited at $222^{\circ} \mathrm{C}$ of final substrate temperature, value of reflective index at top and bottom is the same and at $550 \mathrm{~nm}$ amount 1.6. As results of upward diffusion of $\mathrm{Cr}$ and $\mathrm{Ni}$ atoms observed at $233^{\circ} \mathrm{C}$ of final surface temperature (Fig. 5) the $n$ near the interfacial layer increase to 2.0, whereas at the top $n$ achieved about 1.4 as results of etching process. Finally, low value of reflective index indicates that the microstructure of carbon film is more porous (thereby increase of oxygen concentration in DLC film - see Fig. 5) when film becomes thicker (Fig. 1). For comparison, soft polymer-like layers are characterized by low $n=1.6$ in contrast to dense and hard layers $n=2.4$ [23].

Figure 6 shows the value of hardness and Young's modulus of substrate/film system as a function of final deposition temperature during RF PECVD process. As indicate values of refractive index with increase of substrate temperature decrease value of $H$ and $E$ whereas increase film thickness (Fig. 1). The minimal value of $H=6.9 \mathrm{GPa}$ and $E=180 \mathrm{GPa}$ is observed at most porous films with $n=1.6$ (for comparison the untreated $316 \mathrm{~L}$ stainless steel is characterized by $E \sim 192 \mathrm{GPa}$ ). Subsequent increase of substrate temperature again leads to increase of $H$ and $E$ as results of significant acceleration of formation the interfacial layer. That should be noted as the fact that even for the longest deposition processes with thick interfacial layer and

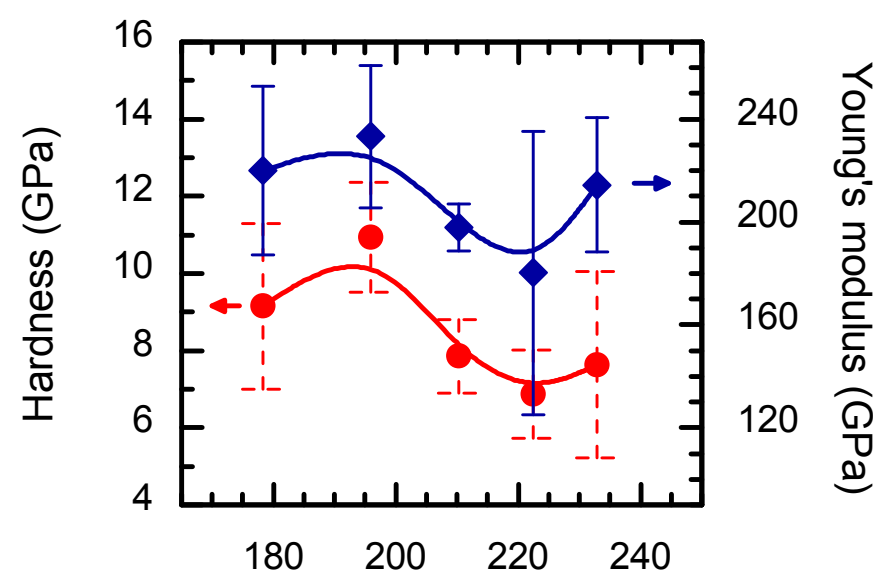

\section{Substrate temperature $\left({ }^{\circ} \mathrm{C}\right)$}

Fig. 6. Hardness and Young's modulus of substrate/film system as a function of final deposition temperature 
higher concentration of carbides no embrittlement was observed during the indentation loading and unloading cycles. Next, the important parameters contributing to the decrease of wear is the low friction coefficient $(\mu)$. All the deposition processes had significant effect on $\mu$ : it varied between 0.07 and 0.10 . For comparison $\mu$ for untreated $316 \mathrm{~L}$ stainless steel was 0.12 under the identical conditions.

These results indicate that the microstructure of carbon film is more porous as a result of the competition between deposition and etching processes when film is deposited at higher substrate temperature activated by high substrate bias. Prior results [24] show that films deposited at lower substrate bias $(<700 \mathrm{~V})$ have more homogeneous structure with a density typically reported $[25,26]$ (reflective index fluctuated between 1.73-1.93 and hardness between 12.3-16.1 GPa [24]).

The microstructures of the DLC films were also investigated by Raman spectrometer. It is well known that the visible Raman band at $514 \mathrm{~nm}$ is directly sensitive to the presence of $s p^{2}$ bonds in carbon, because this photon energy preferentially excites the $\pi$ states at these sites. All the spectra of carbon films obtained in this work display two main features, the broad $G$ peak as well as $D$ peak. The $G$ peak at around $1580-1600 \mathrm{~cm}^{-1}$ has been assigned to the scattering by $s p^{2}$ bonded carbon associated with graphite. The $D$ peak at around $1350 \mathrm{~cm}^{-1}$ is associated with the disorder due to the formation of $s p^{3}$ bonded between graphite adjacent planes [27,28].

More quantitative information can be obtained from these spectra by fitting the $D$ and $G$ peaks to Gaussian lines. The ratio of the $D$ to $G$ peak areas $\left(I_{D} / I_{G}\right)$ calculated through the fitting procedure decreases from 3.2 to 1.2 for films deposited at 155 and $233^{\circ} \mathrm{C}$, respectively (Fig. 7). Whereas $G$ peak position initially increase and achieve maximum $1596 \mathrm{~cm}^{-1}$ at $210^{\circ} \mathrm{C}$. Next, with temperature $G$ peak position rapidly decrease to value 1593 $\mathrm{cm}^{-1}$. It is well known that the $I_{D} / I_{G}$ ratio and $G$ position is used to estimate the content of $s p^{3}$ and $s p^{2}$ fraction in DLC films. Basing on experimental data reported by Ferrari and Robetrson [1] the content of $s p^{3}$ in deposited films have been estimated - their value increases from 0.25 to 0.40 with decrease $I_{D} / I_{G}$ ratio. This means that erosion process of DLC film observed at higher temperature of RF plasma discharge initially preferred etching of $s p^{2}$ phase. This selective process has confirmation in the measurement of optical constants. Namely, the analysis of refractive index indicates that the microstructure of carbon film is more porous when film becomes thicker at higher final surface temperature.

\section{Conclusions}

In the present work, the DLC thin films on the $316 \mathrm{~L}$ stainless steel substrate by RF PECVD process were deposited and systematically have studied the effect of increased temperature of substrate on microstructure and mechanical properties of substrate-film system. Based on ex-situ spectroscopic ellipsometry, X-ray diffraction, X-ray photoelectron spectroscopy

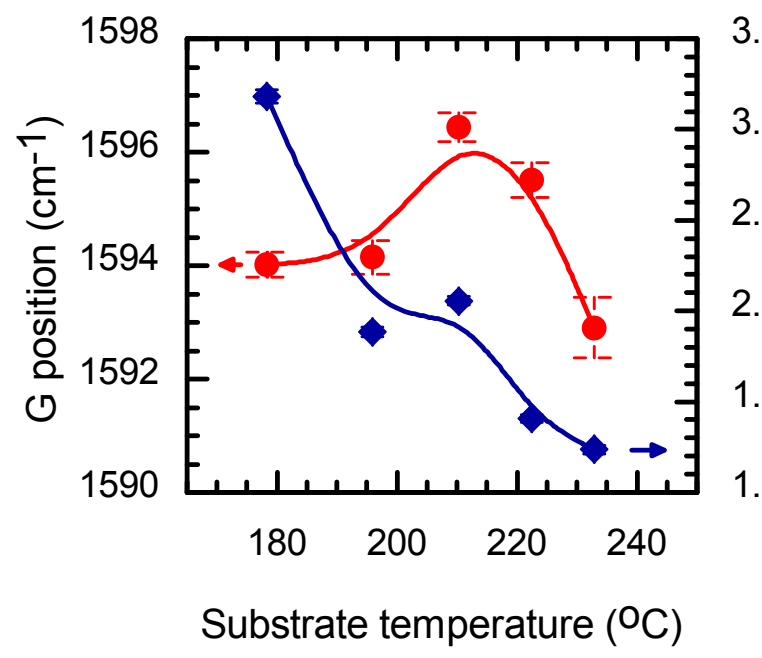

3.5

3.0

2.5

2.0

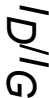

1.5

1.0

Fig. 7. Evolution of the $\mathrm{G}$ position and the $I_{D} / I_{G}$ factor determined by the fitting of the Raman spectra as a function of final deposition temperature.

and Raman spectroscopy measurements three stages model of formation DLC film and steel substrate structure is completed:

- the growth of the diamond-like surface layer,

- $\quad$ onset of $\mathrm{C}$ diffusion into the steel at $210^{\circ} \mathrm{C}$, and

- the growth of chromium carbide interface, the upward diffusion of chromium and nickel atoms to film, and the etching of diamond-like surface layer at $233^{\circ} \mathrm{C}$.

The existence of carbide sublayers was confirmed by ellipsometry and XPS depth profiles measurements. The first two stages of the process are beneficial in terms of decreased friction coefficient. The Young's modulus and hardness remained relatively constant and no surface embrittlement was observed during the indentation experiments.

Ion bombardment by hyperthermal reactive species triggers off increase of substrate temperature leads to etching process of DLC film and reduce temperature of creation chromium carbides. The limit of process temperature was found to be around $210^{\circ} \mathrm{C}$. Exceeding this limit causes the onset of a third stage, i.e., chromium carbide formation that is responsible for destroy the corrosion resistance of $316 \mathrm{~L}$ stainless steel.

\section{Acknowledgements}

The author wishes to thank Prof. L. Martinu and Prof. J. Klemberg-Sapieha (École Polytechnique de Montréal) for opportunity to carry out of XRD, ellipsometry and hardness measurements, as well Dr M. Kozanecki (Lodz University of Technology) for Raman measurements and Dr M. Walock (University of Alabama at Birmingham) for XPS measurements.

\section{REFERENCES}

[1] A.C. Ferrari, J. Robertson, Physical Review B 61, 14095-14107 (2000).

[2] S. Neuville, A. Matthews, Thin Solid Films 515, 6619-6653 (2007). 
[3] E. Mitura, S. Mitura, P. Niedzielski, Z. Has, R. Wolowiec, A. Jakubowski, J. Szmidt, A. Sokolowska, P. Louda, J. Marciniak, B. Koczy, Diamond and Related Materials 3, 896-898 (1994).

[4] S. Mitura, A. Mitura, P. Niedzielski, P. Couvrat, Chaos, Solitons and Fractals 10, 2165-2176 (1999).

[5] W. Okrój, M. Kaminska, L. Klimek, W. Szymanski, B. Walkowiak, Diamond and Related Materials 15, 1535-1539 (2006).

[6] M. Smietana, W.J. Bock, J. Szmidt, J. Grabarczyk, Diamond and Related Materials 19, 1461-1465 (2010).

[7] P.C.T. Ha, D.R. McKenzie, M.M.M. Bilek, E.D. Doyle, D.G. McCulloch, P.K. Chu, Surface and Coatings Technology 200, 6405-6408 (2006)

[8] A. Grill, IBM Journal of Research and Development 43, 147-161 (1999).

[9] Y. Sun, T. Bell, Wear 253, 689-693 (2002).

[10] M. Tsujikawa, D. Yoshida, N. Yamauchi, N. Ueda, T. Sone, S. Tanaka, Surface and Coatings Technology 200, 507-511 (2005).

[11] Y. Sun, Journal of Materials Processing Technology 168, 189-194 (2005).

[12] Z. Has, S. Mitura, M. Clapa, J. Szmidt, Thin Solid Films 136, 161-166 (1986).

[13] S. Mitura, Z. Has, V.I. Gorokhovsky, Surface and Coatings Technology 47, 106-112 (1991).

[14] Guide to Using WVASE 32, J. A. Woollam Co., Inc.

[15] R. Gago, M. Vinnichenko, H.J. Jager, A.Yu. Belov, I. Jimenez, N. Huang, H. Sun, M.F. Maitz, Physical Review B 72, 0141201-014120-9 (2005).
[16] M. Dudek, A. Amassian, O. Zabeida, J.E. Klemberg-Saphieha, L. Martinu, Thin Solid Films 517, 4576-4582 (2009).

[17] W.C. Oliver, G.M. Pharr, Journal of Materials Research 7, 15641583 (1992).

[18] R. Consiglio, N. Durand, K.F. Badawi, P. Macquart, F. Lerbet, M. Assoul, J. von Stebut, Surface and Coatings Technology 97, 192-199 (1997).

[19] A. von Keudell, W. Jacob, Journal of Applied Physics 79, 10921098 (1996)

[20] S. Mitura, Journal of Crystal Growth 80, 417-424 (1987).

[21] A. Guiner, Theorie et Technique de Radiocrystallographie, Dunod, Paris, 1956.

[22] H. Lipson, N.J. Petch, J. Iron Steel Inst. 142, 95 (1940).

[23] T. Schwarz-Selinger, A. von Keudell, and W. Jacob, Journal of Applied Physics 86, 3988-3996 (1999).

[24] A. Kluba, D. Bociaga, M. Dudek, Diamond and Related Materials 19, 533-536 (2010).

[25] G. Capote, F.L. Freire, Materials Science and Engineering B: Solid-State Materials for Advanced Technology 112, 101-105 (2004).

[26] M.A. Tamor, W.C. Vassell, Journal of Applied Physics 76, 38233830 (1994).

[27] R.O. Dillon, J.A. Wollam, and V. Katkanant, Physical Review B 29, 3482-3489 (1984).

[28] H.-C. Tsai, D. B. Bogy, Journal of Vacuum Science and Technology A 5, 3287-3313 (1987). 